\title{
Morbidity associated with patent ductus arteriosus in preterm newborns: a retrospective case-control study
}

\author{
Gianluca Terrin * DE, Maria Di Chiara, Giovanni Boscarino, Valentina Metrangolo, Francesca Faccioli, Elisa Onestà,
} Antonella Giancotti, Violante Di Donato, Viviana Cardilli and Mario De Curtis

\begin{abstract}
Introduction: Association between persistency of a patent ductus arteriosus (PDA) and morbidity in preterm newborns is still controversial. We aimed to investigate the relation between PDA and morbidity in a large retrospective study.
\end{abstract}

Methods: A case-control study including neonates consecutively admitted to the Neonatal Intensive Care Unit (NICU), with gestational age $(G A)<32$ weeks or body birth weight $(B W)<1500$ g, over a 5 -year period. Newborns were divided into Cases and Controls, according with the presence or absence of a hemodynamically significant PDA (hs-PDA).

Results: We enrolled 85 Cases and 193 Controls. Subjects with hs-PDA had significantly $(p<0.001)$ lower GA (26.7 w, 95\%Cl 27.1-28.0 vs. 30.1 w, 95\%Cl 29.7-30.4), BW (1024 g, 95\% Cl 952-1097 vs. $1310 \mathrm{~g} \mathrm{95 \% Cl} \mathrm{1263-1358)} \mathrm{and} \mathrm{an}$ increased morbidity (60.0\% vs. $18.7 \%$ ). In a sub-group of extremely preterm newborns (GA $\leq 28$ weeks and BW $\leq$ $1000 \mathrm{~g}$ ), the rate of bronchopulmonary dysplasia (BPD) was significantly increased in Cases (31.7\%) compared with Controls $(5.9 \%, p=0.033)$. Multivariate analysis showed that morbidity significantly depended on hs-PDA, GA and BW, and that, in extremely preterms, the hs-PDA represented an independent risk factor for BPD.

Conclusions: Occurrence of the main morbidities of prematurity depended by hs-PDA, in association with GA, BW, and use of prenatal steroids. In extremely premature babies, hs-PDA is a risk factor for BPD, one of the most important morbidity of prematurity, independently by other confounding variables.

Keywords: Bronchopulmonary dysplasia (BPD), Necrotizing enterocolitis (NEC), Retinopathy of prematurity (ROP), Intraventricular hemorrhage (IVH), Mortality, Survival, Ibuprofen, Paracetamol

\section{Introduction}

The ductus arteriosus is a vascular structure that connects the proximal descending aorta to the roof of the main pulmonary artery near the origin of the left branch pulmonary artery [1]. The ductus arteriosus normally constricts after birth and becomes functionally closed by the first days of life [2]. Persistency of a patent ductus

\footnotetext{
* Correspondence: gianluca.terrin@uniroma1.it

Department of Maternal and Child Health, University of Rome La Sapienza, Rome, Italy
}

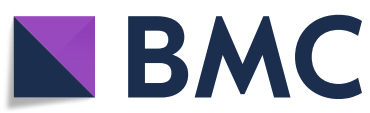

(c) The Author(s). 2021 Open Access This article is licensed under a Creative Commons Attribution 4.0 International License, which permits use, sharing, adaptation, distribution and reproduction in any medium or format, as long as you give appropriate credit to the original author(s) and the source, provide a link to the Creative Commons licence, and indicate if changes were made. The images or other third party material in this article are included in the article's Creative Commons licence, unless indicated otherwise in a credit line to the material. If material is not included in the article's Creative Commons licence and your intended use is not permitted by statutory regulation or exceeds the permitted use, you will need to obtain permission directly from the copyright holder. To view a copy of this licence, visit http://creativecommons.org/licenses/by/4.0/. The Creative Commons Public Domain Dedication waiver (http://creativecommons.org/publicdomain/zero/1.0/) applies to the data made available in this article, unless otherwise stated in a credit line to the data.

arteriosus (PDA) is a common issue in extremely low birth infants. Particularly, in those extremely low birth weight (ELBW) newborns, the duct fails to close leading to a left heart volume overload and systemic hypoperfusion [2]. Clinical consequences of this hemodynamic condition are still controversial. It is worth of mentioning that the effects of a hemodynamically significant PDA (hs-PDA) on neonatal morbidities remain widely unproven. If a body of evidence suggests an increase in the morbidity associated with PDA, recent randomized 
controlled studies and metanalysis have failed to demonstrate a causal relationship [2-5]. However, an association between PDA and morbidity in ELBW newborns cannot be definitive excluded from current literature review. In addition, in many studies criteria for diagnosis hs-PDA were not clearly described.

The purpose of this study was to investigate the association between the presence of PDA and the occurrence of morbidities in very low birth weight (VLBW) newborns, focusing on newborns with gestational age (GA) $\leq$ 28 weeks and birth weight $(\mathrm{BW}) \leq 1000 \mathrm{~g}$.

\section{Methods}

\section{Study design and population}

This is a case-control study including all neonates consecutively admitted to the Neonatal Intensive Care Unit (NICU) of Policlinico Umberto I Hospital, La Sapienza University of Rome, from April 2015 to March 2020, with GA $<32$ weeks or body $B W<1500$ g. We excluded newborns with incomplete clinical data, major congenital malformations, inborn errors of metabolism, intestinal and extra-intestinal congenital diseases, familiar history of allergy, use of pre-or probiotics, transfer to other hospital or death within the first $72 \mathrm{~h}$ of life [6-11].

The enrolled subjects were divided into 2 Groups according to the presence (Cases) or absence (Controls) of a hs-PDA, confirmed by echocardiographic evaluation. We defined PDA, as hemodynamically significant, when we observed at least one of the following criteria, other than PDA diameter at its narrowest part $\geq 1.5 \mathrm{~mm}:$ 1) unrestrictive pulsatile transductal flow; 2) left atrial-to-aortic root ratio $\geq 1.5$; 3) absent diastolic flow in descending aorta; 4) abnormal diastolic flow in middle cerebral artery [5, 12-14]. Echocardiography $(\mathrm{ECHO})$ was routinely performed by cardiologists trained in neonatal functional ECHO between 24 and $72 \mathrm{~h}$ after birth, in all premature infants admitted in NICU. A second echocardiographic evaluation was performed at 7 days of life. The ECHO evaluation was performed by two cardiologists with high training, unaware of the study aims. Each measurement was confirmed after an agreement between the two cardiologists. They performed each measurement three times and then reported the mean value in a specific data form.

Newborns were classified as Cases when affected by hs-PDA, confirmed by echocardiographic evaluations performed during the first week of life. We classified as Controls all newborns without hs-PDA during hospital stay. Pediatric cardiologists performed ultrasound studies and the treatment was eventually decided after an agreement between cardiologists and neonatologists on duty.
To conduct this research, we compared two historical Groups of newborns using data collected during a study previously approved by Ethical Committee ( $\left.{ }^{\circ} 5089\right)$. We obtained a written informed consent from all parents of enrolled newborns. This study was conducted in conformity with World Medical Association Declaration of Helsinki for medical research involving human subjects.

\section{Outcomes}

We considered as primary outcome the rate of newborns with at least one of the following morbidities, before discharge from the NICU: prolonged mechanical ventilation (more than 7 days), bronchopulmonary dysplasia (BPD), intraventricular haemorrhage (IVH) stage $\geq 2$, necrotizing enterocolitis (NEC) Bell-Stage $\geq 2$, retinopathy of prematurity (ROP) stage $\geq 3$, hypotension [1, 2, 15-17]. We considered as secondary outcomes the mortality and the duration of hospital stay.

\section{Data collection}

Investigators who were not involved in the enrollment phases, recorded clinical data using a structured data form, from birth to discharge, transfer to another hospital or death of the patient. We collected data about gender, GA, BW, twin pregnancies, type of delivery, use of antenatal steroids, pregnancy-induced hypertension, alteration of Doppler velocimetry on uterine arteries, $\mathrm{pH}$ on cord blood and Apgar score at $5 \mathrm{~min}$.

Diagnosis of the main neonatal morbidities were performed according to the standard criteria, by physicians unaware of the study design and aims, as previously described [18-20]. Nutritional management was performed as previously described $[18,21-23]$. We collected data on morbidity and duration of hospital stay in a separate and codified data form.

\section{Statistics}

Statistical analysis was performed per protocol, using Statistical Package for Social Science software for Microsoft Windows (SPSS Inc., Chicago, IL), and version 25.0. We checked for normality using Shapiro-Wilk test. The mean and 95\% confidence interval (CI) summarised continuous variables. We compared the Groups using chisquare test for categorical variable and t-test or MannWhitney for paired and unpaired variables.

We performed a sensitivity analysis, including a subgroup of patients with GA $\leq 28$ weeks (Sub-group A) and $\mathrm{BW} \leq 1000 \mathrm{~g}$ (Sub-group B). We performed a binary logistic regression analysis to evaluate whether gender (female or male), GA ( $<29$ or $\geq 29$ weeks of PMA) or BW ( $\leq 1000$ or $>1000 \mathrm{~g})$, use of prenatal steroids, $\mathrm{pH}$ at birth $(<7.1$ or $\geq 7.1)$, and Group (Case or Control) or Sub-Group assignment (A or B) influenced primary outcome. We performed linear regression analysis to 
evaluate if gender, GA or BW and antenatal steroids or pregnancy-induced hypertension influenced duration of hospitalization. The level of significance for all statistical tests was 2 -sided $(p<0.05)$.

\section{Results}

We considered eligible for the study 343 newborns. We excluded 65 neonates because of congenital malformations, congenital infections, maternal autoimmune diseases $(n=29)$, early transfer to other hospital $(n=21)$ or death $(n=15)$. Thus, we included 278 infants, 85 as Cases (30.6\%) and 193 as Controls (69.4\%).

The main clinical characteristics of participating Cases and Controls subjects were summarized in Table 1 . We observed that infants with hs-PDA had lower GA, BW, Apgar scores at $5 \mathrm{~min}$, rate of administration of antenatal steroids and $\mathrm{pH}$ on cord blood.

The overall morbidity was significantly increased in Cases compared with Controls (Table 2). The risk of prolonged mechanical ventilation, BPD, IVH, ROP and hypotension was increased in Cases compared with Controls (Table 2). The rate of mortality was increased in Cases $(10.6 \%)$ compared with Controls $(3.6 \%, p=0.025)$. Mean duration of hospital stay was increased in newborns with hs-PDA (80.4 days, 95\%CI 69.4 to 91.4) compared with Controls (54.9 days, 95\%CI 50.9 to 58.9, $p<0.001$ ).

Multivariate analysis showed that morbidity was significantly related to the occurrence of a hs-PDA, in both models including GA and BW, respectively (Table 3). Mortality was not influenced by the presence of a hsPDA but depended only on GA and BW (Table 3). Multivariate linear regression analysis showed that duration of hospital stay was influenced by the occurrence of hs-PDA along with $\mathrm{GA} \leq 28$ weeks, BW $\leq 1000 \mathrm{~g}$ and the administration of antenatal steroids, in all enrolled newborns (Table S1).

When we analyzed Sub-group of children with GA $\leq$ 28 weeks and $\mathrm{BW} \leq 1000 \mathrm{~g}$, we found similar baseline characteristics, between Cases and Controls, but an increased rate of mother with pregnancy-induced hypertension and occurrence of BPD in those with hs-PDA compared with Controls (Tables 1 and 2). The mortality rate was similar between Cases (19.5\%) and Controls $(27.8 \%)$ in this sensitivity analysis. In this Sub-Group of patients, we observed that the mean length of hospital stay was significantly increased in Cases $(98.8,95 \% \mathrm{CI}$ 79.0 to 118.7$)$ compared with Controls $(64.4,95 \% \mathrm{CI} 44.6$ to $84.2, p=0.034$ ).

In a sensitivity binary logistic regression analysis, including newborns of Sub-groups A and B, hs-PDA was a significant and independent factor associated with occurrence of BPD (Table 4).

We observed, in a sensitivity linear logistic regression analysis, that hs-PDA was not an independent and significant risk factor for length of hospital stay (Table S1).

\section{Discussion}

In our population of newborns, with $\mathrm{GA}<32$ weeks or $\mathrm{BW}<1500 \mathrm{~g}$, occurrence of the main morbidities of prematurity seems to be related to hs-PDA. However, this observed association depended also on GA, BW, and use of prenatal steroids. When we corrected data for confounding variables, we confirmed that hs-PDA represents a risk factor for the occurrence of prolonged mechanical ventilation, BPD, IVH, ROP, and hypotension, but along with GA, BW and prenatal use of steroids. In other words, in keeping with our findings,

Table 1 Clinical characteristics of study population

\begin{tabular}{|c|c|c|c|c|}
\hline & \multicolumn{2}{|l|}{ Overall } & \multicolumn{2}{|c|}{$\begin{array}{l}\text { Gestational Age } \leq 28 \text { weeks and Birth } \\
\text { Weight } \\
\leq 1000 \mathrm{~g}\end{array}$} \\
\hline & $\begin{array}{l}\text { Case Group } \\
(n=85)\end{array}$ & $\begin{array}{l}\text { Control Group } \\
(n=193)\end{array}$ & $\begin{array}{l}\text { Case Group } \\
(n=41)\end{array}$ & $\begin{array}{l}\text { Control Group } \\
(n=18)\end{array}$ \\
\hline Female sex, N. (\%) & $41(48.2)$ & $87(45.1)$ & $22(53.7)$ & $8(44.4)$ \\
\hline Gestational Age, weeks & $27.6(27.1$ to 28.0$) *$ & $30.1(29.7$ to 30.4$)$ & 25.9 (25.4 to 26.4$)$ & $26.0(25.1$ to 26.9$)$ \\
\hline Birth weight, $g$ & $1024(952$ to 1097$) *$ & 1310 (1263 to 1358$)$ & 754.1 (709.6 to 798.6$)$ & 769.5 (681.2 to 875.8$)$ \\
\hline Twins, N. (\%) & $23(27.1)$ & $54(28.0)$ & $8(19.5)$ & $5(27.8)$ \\
\hline Cesarean Section, N. (\%) & $69(82.1)$ & $168(88.4)$ & $27(65.8)$ & $13(72.2)$ \\
\hline Antenatal steroids ${ }^{a}, N .(\%)$ & $49(59.8) *$ & $139(73.5)$ & $28(68.3)$ & $12(66.7)$ \\
\hline Pregnancy-induced hypertension, N. (\%) & $20(26.3)$ & $46(24.1)$ & $14(34.1) *$ & $1(5.5)$ \\
\hline Alteration of doppler velocimetry of uterine arteries, N. (\%) & $14(19.4)$ & $35(18.5)$ & $3(7.3)$ & $3(16.7)$ \\
\hline pH on cord blood & $7.2(7.2$ to 7.3$) *$ & 7.3 (7.2 to 7.3$)$ & 7.2 (7.2 to 7.3$)$ & 7.2 (7.2 to 7.3$)$ \\
\hline 5-min Apgar score & $7(6$ to 7$) *$ & 8 (7 to 8$)$ & 6.6 (6.1 to 7.1$)$ & 7.1 (6.5 to 7.6$)$ \\
\hline
\end{tabular}

Data were expressed as mean $(95 \% \mathrm{Cl})$, when not specified

$\left({ }^{\mathrm{a}}\right)$ Intramuscular steroid cycle in two doses of $12 \mathrm{mg}$ over a $24-\mathrm{h}$ period; * vs Control Group $p<0.05$. 
Table 2 Morbidity associated with hemodynamic significant patent ductus arteriosus

\begin{tabular}{|c|c|c|c|c|}
\hline & \multicolumn{2}{|l|}{ Overall } & \multicolumn{2}{|c|}{$\begin{array}{l}\text { Gestational Age } \leq 28 \text { weeks and Birth Weight } \\
\leq 1000 \mathrm{~g}\end{array}$} \\
\hline & $\begin{array}{l}\text { Case Group } \\
(n=85)\end{array}$ & $\begin{array}{l}\text { Control Group } \\
(n=193)\end{array}$ & $\begin{array}{l}\text { Case Group } \\
(n=41)\end{array}$ & $\begin{array}{l}\text { Control Group } \\
(n=18)\end{array}$ \\
\hline Prolonged Mechanical Ventilation & $19(22.4) *$ & $11(5.7)$ & $17(41.5)$ & $3(16.7)$ \\
\hline Bronchopulmonary Dysplasia & $13(15.3) *$ & $6(3.1)$ & $13(31.7) *$ & $1(5.9)$ \\
\hline Intraventricular Hemorrhage & $17(20.0) *$ & $8(4.1)$ & $12(29.3)$ & $4(22.2)$ \\
\hline Necrotizing Enterocolitis & $1(1.2)$ & $5(2.6)$ & $1(2.4)$ & $1(5.6)$ \\
\hline Retinopathy of prematurity & $18(21.2) *$ & $5(2.6)$ & $14(34.1)$ & $2(11.1)$ \\
\hline Hypotension & $27(31.8) *$ & $11(5.7)$ & $19(46.3)$ & $6(33.3)$ \\
\hline Overall Morbidity ${ }^{a}$ & $51(60.0) *$ & 36 (18.7) & $34(82.9)$ & $12(66.7)$ \\
\hline
\end{tabular}

Data were expressed as No. (\%)

$\left({ }^{a}\right)$ BPD or Prolonged mechanical ventilation or IVH or NEC or ROP or Hypothension; * vs Control Group $p<0.05$

it is not possible to exclude that morbidity depends on factors other than hs-PDA.

We observed a different scenario in extremely premature babies ( $\mathrm{GA} \leq 28$ weeks and $\mathrm{BW} \leq 1000 \mathrm{~g}$ ). In particular, hs-PDA resulted as an independent risk factor for BPD, which is one of the most important morbidity of prematurity, in newborns with GA $\leq 28$ weeks and $\mathrm{BW} \leq 1000 \mathrm{~g}$, even if we corrected data for GA.
Finally, we showed that the presence of hs-PDA may increase the duration of hospitalization in enrolled newborns.

It has been hypothesized that hemodynamic condition generated by hs-PDA may induce different organs injuries, leading to an increased risk of clinical complications [24]. Despite it is clinical plausible, there is still uncertainty from current evidence regarding possible association between hs-PDA, morbidity and mortality in

Table 3 Multivariate analysis evaluating confounding variables on morbidity and mortality

\begin{tabular}{|c|c|c|c|c|c|c|c|c|}
\hline \multirow{2}{*}{$\begin{array}{l}\text { Dependent } \\
\text { variables }\end{array}$} & \multicolumn{4}{|c|}{ Covariates (Model 1) } & \multicolumn{4}{|c|}{ Covariates (Model 2) } \\
\hline & hs-PDA & Gender & $\mathrm{GA} \leq 28$ weeks & $\begin{array}{l}\text { Antenatal } \\
\text { steroidsa }\end{array}$ & hs-PDA & Gender & $\mathrm{BW} \leq 1000 \mathrm{~g}$ & $\begin{array}{l}\text { Antenatal } \\
\text { steroids }^{a}\end{array}$ \\
\hline \multicolumn{9}{|c|}{ Prolonged Mechanical Ventilation } \\
\hline $\begin{array}{l}\text { OR } \\
(95 \% C l)\end{array}$ & $\begin{array}{l}2.567(1.063 \text { to } \\
6.202) *\end{array}$ & $\begin{array}{l}1.498(0.650 \\
\text { to } 3.454)\end{array}$ & $\begin{array}{l}6.471(2.385 \text { to } \\
17.561) *\end{array}$ & $\begin{array}{l}1.171(0.474 \text { to } \\
2.892)\end{array}$ & $\begin{array}{l}2.335(0.953 \text { to } \\
5.721)\end{array}$ & $\begin{array}{l}1.411(0.603 \\
\text { to } 3.305)\end{array}$ & $\begin{array}{l}7.441(2.919 \text { to } \\
18.969) *\end{array}$ & $\begin{array}{l}1.094(0.440 \text { to } \\
2.720)\end{array}$ \\
\hline \multicolumn{9}{|c|}{ Bronchopulmonary Dysplasia } \\
\hline $\begin{array}{l}\text { OR } \\
(95 \% C l)\end{array}$ & $\begin{array}{l}4.358(1.386 \text { to } \\
13.702) *\end{array}$ & $\begin{array}{l}1.744(0.594 \\
\text { to } 5.117)\end{array}$ & $\begin{array}{l}3.121(0.951 \text { to } \\
10.241)\end{array}$ & $\begin{array}{l}10.698(1.350 \text { to } \\
84.789 *\end{array}$ & $\begin{array}{l}2.188(0.661 \text { to } \\
7.240)\end{array}$ & $\begin{array}{l}1.646(0.538 \\
\text { to } 5.037)\end{array}$ & $\begin{array}{l}13.270(3.235 \text { to } \\
54.441) *\end{array}$ & $\begin{array}{l}9.937(1.240 \text { to } \\
79.634)^{*}\end{array}$ \\
\hline \multicolumn{9}{|c|}{ Intraventricular Hemorrhage } \\
\hline $\begin{array}{l}\text { OR } \\
(95 \% C l)\end{array}$ & $\begin{array}{l}3.184(1.170 \text { to } \\
8.666) *\end{array}$ & $\begin{array}{l}1.223(0.488 \\
\text { to } 3.065)\end{array}$ & $\begin{array}{l}7.182(2.219 \text { to } \\
23.244) *\end{array}$ & $\begin{array}{l}0.518(0.204 \text { to } \\
1.316)\end{array}$ & $\begin{array}{l}3.850(1.427 \text { to } \\
10.390) *\end{array}$ & $\begin{array}{l}1.138(0.457 \\
\text { to } 2.834)\end{array}$ & $\begin{array}{l}4.214(1.591 \text { to } \\
11.162) *\end{array}$ & $\begin{array}{l}0.498(0.197 \text { to } \\
1.258)\end{array}$ \\
\hline \multicolumn{9}{|c|}{ Retinopathy of Prematurity } \\
\hline $\begin{array}{l}\text { OR } \\
(95 \% \mathrm{Cl})\end{array}$ & $\begin{array}{l}4.083(1.339 \text { to } \\
12.447)^{*}\end{array}$ & $\begin{array}{l}1.028(0.387 \\
\text { to } 2.729)\end{array}$ & $\begin{array}{l}12.174(2.621 \text { to } \\
56.552) *\end{array}$ & $\begin{array}{l}1.077 \text { (0.379 to } \\
3.057)\end{array}$ & $\begin{array}{l}4.594(1.496 \text { to } \\
14.102) *\end{array}$ & $\begin{array}{l}0.927(0.349 \\
\text { to } 2.463)\end{array}$ & $\begin{array}{l}6.178(2.016 \text { to } \\
18.936) *\end{array}$ & $\begin{array}{l}0.977(0.347 \text { to } \\
2.749)\end{array}$ \\
\hline \multicolumn{9}{|l|}{ Hypotension } \\
\hline $\begin{array}{l}\text { OR } \\
(95 \% C l)\end{array}$ & $\begin{array}{l}4.834(2.047 \text { to } \\
11.418) *\end{array}$ & $\begin{array}{l}0.793(0.357 \\
\text { to } 1.760)\end{array}$ & $\begin{array}{l}7.563(2.874 \text { to } \\
19.899) *\end{array}$ & $\begin{array}{l}1.455(0.607 \text { to } \\
3.490)\end{array}$ & $\begin{array}{l}5.723(2.446 \text { to } \\
13.393) *\end{array}$ & $\begin{array}{l}0.732(0.334 \\
\text { to } 1.604)\end{array}$ & $\begin{array}{l}3.798(1.676 \text { to } \\
8.605) *\end{array}$ & $\begin{array}{l}1.373(0.589 \text { to } \\
3.204)\end{array}$ \\
\hline \multicolumn{9}{|l|}{ Morbidity $^{\circ}$} \\
\hline $\begin{array}{l}\text { OR } \\
(95 \% C l)\end{array}$ & $\begin{array}{l}4.058(2.145 \text { to } \\
7.677) *\end{array}$ & $\begin{array}{l}1.072(0.581 \\
\text { to } 1.979)\end{array}$ & $\begin{array}{l}5.227(2.814 \text { to } \\
9.708) *\end{array}$ & $\begin{array}{l}0.974(0.502 \text { to } \\
1.890)\end{array}$ & $\begin{array}{l}4.109(2.160 \text { to } \\
7.819) *\end{array}$ & $\begin{array}{l}1.023(0.548 \\
\text { to } 1.912)\end{array}$ & $\begin{array}{l}6.596(3.441 \text { to } \\
12.643) *\end{array}$ & $\begin{array}{l}0.986(0.507 \text { to } \\
1.919)\end{array}$ \\
\hline \multicolumn{9}{|l|}{ Mortality } \\
\hline $\begin{array}{l}\text { OR } \\
(95 \% C l)\end{array}$ & $\begin{array}{l}1.307 \text { (0.414 to } \\
4.126)\end{array}$ & $\begin{array}{l}1.205(0.396 \\
\text { to } 3.664)\end{array}$ & $\begin{array}{l}26.178(3.210 \text { to } \\
213.479) *\end{array}$ & $\begin{array}{l}0.475(0.154 \text { to } \\
1.468)\end{array}$ & $\begin{array}{l}1.519(0.470 \text { to } \\
4.908)\end{array}$ & $\begin{array}{l}1.148(0.373 \\
\text { to } 3.540)\end{array}$ & $\begin{array}{l}10.977(2.787 \text { to } \\
43.230) *\end{array}$ & $\begin{array}{l}0.473(0.153 \text { to } \\
1.460)\end{array}$ \\
\hline
\end{tabular}

hs-PDA hemodynamically significant Patent Doctus Arteriosus

(a) Intramuscular steroid cycle in two doses of $12 \mathrm{mg}$ over a 24 -h period; ${ }^{\circ}$ BPD or NEC or IVH or PLV or ROP or Prolonged mechanical ventilation or Hypotension requiring treatment; ${ }^{*} p<0.05$ 
Table 4 Binary logistic regression analysis evaluating influence of covariates on morbidity and mortality in study population with gestational age $\leq 28$ weeks and birth weight $\leq 1000 \mathrm{~g}$

\begin{tabular}{|c|c|c|c|}
\hline \multirow{2}{*}{$\begin{array}{l}\text { Dependent } \\
\text { variabels }\end{array}$} & \multicolumn{3}{|l|}{ Covariates } \\
\hline & hs-PDA & Gender & $\begin{array}{l}\text { Pregnancy-induced } \\
\text { hypertension }\end{array}$ \\
\hline \multicolumn{4}{|c|}{ Prolonged Mechanical Ventilation } \\
\hline OR $(95 \% C l)$ & 3.097 (0.731 to 13.132$)$ & $1.210(0.391$ to 3.750$)$ & 1.415 (0.398 to 5.033$)$ \\
\hline \multicolumn{4}{|c|}{ Bronchopulmonary Dysplasia } \\
\hline OR $(95 \% C l)$ & $8.489(0.968$ to 74.435$) *$ & 2.112 (0.572 to 7.800$)$ & 0.689 (0.166 to 2.859$)$ \\
\hline \multicolumn{4}{|c|}{ Intraventricular Hemorrhage } \\
\hline OR $(95 \% C l)$ & 1.466 (0.365 to 5.894$)$ & 2.870 (0.834 to 9.878$)$ & 0.713 (0.173 to 2.946$)$ \\
\hline \multicolumn{4}{|c|}{ Retinopathy of Prematurity } \\
\hline OR $(95 \% C l)$ & 3.553 (0.674 to 18.742$)$ & 0.865 (0.260 to 2.879$)$ & 1.583 (0.424 to 5.903$)$ \\
\hline \multicolumn{4}{|l|}{ Hypotension } \\
\hline OR $(95 \% C l)$ & 2.405 (0.669 to 8.649$)$ & 0.823 (0.278 to 2.440$)$ & $0.520(0.141$ to 1.924$)$ \\
\hline \multicolumn{4}{|l|}{ Morbidity $^{\circ}$} \\
\hline OR $(95 \% C l)$ & 2.671 (0.674 to 10.592$)$ & 1.248 (0.349 to 4.462$)$ & 0.853 (0.176 to 4.139$)$ \\
\hline \multicolumn{4}{|l|}{ Mortality } \\
\hline$O R(95 \% C l)$ & 0.899 (0.211 to 3.830$)$ & 2.212 (0.548 to 8.932 ) & 0.209 (0.023 to 1.915$)$ \\
\hline
\end{tabular}

or ROP or Prolonged mechanical ventilation or Hypothension; ${ }^{*} p<0.05$

VLBW infants. Randomized controlled trials (RCTs) did not clarify whether PDA may have clinical consequences in this population, whereas, several not controlled studies found a relation between symptomatic hs-PDA, morbidity and mortality [25-28]. A retrospective study, exploring the impact of PDA on survival, found that mortality rate was higher among preterm infants with PDA [2]. In those studies, it is not possible to determine if the adverse neonatal outcomes observed in preterm newborns can be referred to hs-PDA or to GA.

In this study, all patients enrolled had a hs-PDA and confidence intervals for the odds for mortality were relatively wide. We found that hs-PDA influenced morbidity in a more complex regression model, but solely in association with other variables. Contemporarily, we observed that hs-PDA did not independently affect survival, neither in VLBW nor in extremely low gestational age neonates (ELGAN) and ELBW infants. In addition, that the presence of a hs-PDA could, in turn, depend on GA and BW. Thus, the clinical validity of the multivariate model, used in this study, should take into account this aspect.

Our results suggest that the presence of hs-PDA may prolong the duration of mechanical ventilation. A persistent shunt, increasing the pulmonary blood flow, can lead to pulmonary edema, loss of lung compliance, and deterioration of respiratory status. In a retrospective cohort study was assessed the relation between PDA and prolonged mechanical ventilation in preterm newborns $[25,29]$. Although a causal association has not been proven, the link was greatest among infants born at lower gestational age who were treated with mechanical ventilation in the presence of a large ductal shunt [29]. In addition, authors did not perform a multivariate analysis in order to confirm their findings adjusted for other covariates. We did not found any association between hs-PDA and occurrence of prolonged mechanical ventilation in ELGAN and ELBW enrolled in our study, neither in univariate analysis nor in multivariate analysis. However, the difference in the rate of patients with prolonged mechanical ventilation, observed between Cases and Controls, might become significant in a larger population of ELGAN and ELBW newborns.

Prolonged mechanical ventilation could be also a condition that may have increased the risk of BPD in enrolled newborns affected by hs-PDA. It has been well described by Willis et al. that prolonged mechanical ventilation in preterm newborns can determine alveolar simplification leading to increased likely to develop BPD [30]. Epidemiological studies demonstrated a strong association between the presence of a PDA and the development of BPD [30].

A causative relation between the PDA and the development of BPD was suggested by observational retrospective evidence $[28,31]$. Schena et al. estimated that occurrence of BPD depended on severity of hs-PDA exposure. El-Khuffash et al. in a study exploring possible prognostic values of a PDA score based on echocardiography measurements found that association between PDA and BPD strengthens with decreasing gestational 
age [24]. On the other hand, in a recent study comparing mandatory closure vs. a non-interventional approach to manage hs- PDA in preterm newborns, despite longer PDA exposure, the non-interventional approach was associated with significantly less BPD [32]. However, all newborns with hs-PDA enrolled in this study required ventilatory treatment, which could have influenced the occurrence of BPD. We observed a relation between hsPDA and BPD still when we corrected the data for confounding variables including GA and BW. This association was observed in a multivariate analysis performed in the Sub-group of ELGAN and ELBW subjects. However, the significance of multivariate model suggests that further studies, including a larger number of preterm newborns, should be performed to confirm these findings.

We observed a relation between hs-PDA and IVH a suggested by previous retrospective studies. A large retrospective cohort study on VLBW infants demonstrated that the rate of spontaneous closure before hospital discharge occurs in the majority of patients. However, the Authors excluded the deceased infants from the analysis, whose cause of death was reported to be potentially related to PDA, including IVH and all of them had documented PDA [33]. Our multivariate analysis showed that hs-PDA was a risk factor in association with GA and BW for IVH. Further studies are needed to establish the causality between hemodynamic consequences of PDA and occurrence of IVH.

We showed the association between PDA and ROP, as observed in previous studies. Results from recent wide prospective study showed that PDA requiring medication significantly correlated with the development of ROP. This research, as well as our study, found that PDA was significantly correlated with ROP in the multivariate logistic regression analysis adjusted for GA and $\mathrm{BW}$ [34]. It is known that $\mathrm{pO}_{2}$ regulates the production of predominant regulators of retinal angiogenesis, therefore $\mathrm{O}_{2}$ therapy could be responsible for the retinal damage associated with ROP pathogenesis [35]. However, taking these results into account, it is possible to hypothesize that hs-PDA, in critical ill newborns, may contribute to increase the risk of ROP due to hemodynamic instability that, in turn, may influence development of the immature and incompletely vascularized retina [36]. We did not observe the association between hs-PDA and ROP in ELGAN and ELBW patients. Probably, in these subjects, the extremely immaturity of retina vascularization represents a major risk factor for ROP independently by the presence of hsPDA.

We observed a significant increased risk of hypotension in newborns with hs-PDA. Our findings are in keeping with the results of Ratner et al. who showed that a hs-PDA was associated with a reduction in systolic and diastolic blood pressure [37]. Although it is true that a moderate-to-large PDA can lower systemic blood pressure and is associated with the presence of hypotension at the end of the first week [14, 38, 39], no studies to date has determined whether the PDA actually is responsible for the hypotension or whether its presence is just a surrogate for nonspecific causes related to immaturity/illness. Our multivariate analysis suggested that hypotension in preterm newborns depend contemporarily on hs-PDA, BW and GA. However, the hs-PDA does not seem to influence the occurrence of hypotension in ELGAN and ELBW subjects. Clinical validity of these results should be confirmed in a specifically designed clinical trial focused on hypotension.

A causal relationship between pregnancy-induced hypertension and occurrence of PDA has been described in previous studies. According with a recent Cohort research, we demonstrated a higher rate of pregnancyinduced hypertension in Cases compared with Controls. That increased risk for developing PDA in newborns of women with preeclampsia has been attributed to the likelihood of shared angiogenic imbalance between the mother and fetus [40-42]. However, this relation did not persist in our multivariate analysis.

A large number of previous piece of research have included infants with PDA regardless of hemodynamic significance [43-45]. Therefore, any effect of PDA may have been masked by the absence of clinical consequences of a physiological condition.

Our results should be interpreted considering study limitations. The association between hs-PDA and morbidity outcome in VLBW may be related to the effects of chance, random error, bias or confounding factors. We verified that effect on the main outcome of the study persisted even after correction for confounding variables. Despite of everything, other confounding variables, unknown or not considered in our statistical analysis, may have influenced the study results. In addition, covariate "hs-PDA" could dependent by GA and BW.

We designed a Case-Control study. We observed difference in the baseline clinical characteristics between the two Groups of newborns enrolled in the study. To overcome this limit, we performed a multivariate analysis. However, in this analysis, hs-PDA represent a risk factor for morbidity only in association with other confounding variables such as GA, BW and use of prenatal steroids. Despite of everything, other confounding variables, unknown or not considered in our statistical analysis, may have influenced the study results. We also performed a Subgroup analysis for a population of newborns with $\mathrm{GA} \leq 28$ weeks and $\mathrm{BW} \leq 1000 \mathrm{~g}$. In this way, we analyzed a Sub population with similar GA, overcoming the limitations of its retrospective design. 
However, the small number of patience included in this sub-analysis limit the generalization of results. Further studies are necessary to better address this issue.

The ECHO data include only such variables useful for assessing the hemodynamic significance of a PDA. Despite other parameters (e.g. left ventricular output, pulmonary vein flowmetry and isovolemic relaxation time) could be useful to define hemodynamic role of PDA, these informations are not registered in the clinical charts of the patience, and thus are not available for our retrospective study. Assessing PDA significance by $\mathrm{ECHO}$, is labor-intensive, requires significant skill and is subject to considerable operator variability. In our policy, we preferred to use ECHO parameters for which our cardiologists had high expertise. However, there is a lack of accuracy for a standard definition of hs-PDA. Thus, different diagnostic assessments could have led to different conclusions. To limit observer bias, researchers unaware for study aims collected the data for the analysis, a third party observer was involved to collect data on the outcome of the study, and a blinded statistician performed the data analysis. Finally, Results regarding population of ELGAN and ELBW newborns should be interpreted considering the small number of subjects enrolled as Controls compared with Cases.

\section{Conclusion}

In conclusion, the presence of hs-PDA does not seem to influence the clinical course of VLBW newborns, but only that of ELGAN and ELBW newborns. Potential association between hs-PDA and BPD, found in our casecontrol retrospective study, encourages designing a randomized trial, that should include an adequate number of critical newborns, with $\mathrm{GA} \leq 28$ weeks and $\mathrm{BW} \leq$ $1000 \mathrm{~g}$.

\section{Supplementary Information}

The online version contains supplementary material available at https://doi. org/10.1186/s13052-021-00956-2.

\section{Additional file 1.}

\section{Abbreviations}

PDA: Patent ductus arteriosus; ELBW: Extremely low birth weight; hsPDA: Hemodynamic significant patent ductus arteriosus; VLBW: Very low birth weight; GA: Gestational age; BW: Birth weight; NICU: Neonatal intensive care unit; ECHO: Echocardiography; BPD: Bronchopulmonary dysplasia; IVH: Intraventricular hemorrhage; NEC: Necrotizing enterocolitis; ROP: Retinopathy of prematurity; RCTs: Randomized clinical trials; ELGA $\mathrm{N}$ : Extremely low gestational age

\section{Acknowledgments}

None.

\section{Authors' contributions}

G.T., M.D.C. (Maria Di Chiara), G.B., V.M. conceptualized and designed the study, organized the acquisition of data and reviewed and revised both analyses and the manuscript; G.T., M.D.C. (Maria Di Chiara), G.B., V.M., F.F., E.O.,
A.G.,V.D.D., V.C. and M.D.C. (Mario De Curtis) drafted the article and revised it critically for important intellectual content; all the authors approved the final manuscript to be published.

\section{Funding}

This research received no external funding.

\section{Competing interests}

The authors declare no conflict of interest.

Received: 6 August 2020 Accepted: 4 January 2021

Published online: 14 January 2021

\section{References}

1. Bhat R, Das UG. Management of Patent Ductus Arteriosus in premature infants. Indian J Pediatr. 2015;82:53-60.

2. Benitz WE. Treatment of persistent patent ductus arteriosus in preterm infants: time to accept the null hypothesis? J Perinatol. 2010;30:241-52.

3. Kluckow M, Jeffery M, Gill A, Evans N. A randomised placebo-controlled trial of early treatment of the patent ductus arteriosus. Arch Dis Child - Fetal Neonatal Ed. 2014;99:F99-104.

4. Ohlsson A, Shah SS. Ibuprofen for the prevention of patent ductus arteriosus in preterm and/or low birth weight infants. Cochrane Neonatal Group, editor. Cochrane Database Syst Rev. 2020. https://doi.org/10.1002/ 14651858.CD004213.pub5 cited 2020 Jul 23.

5. El-Khuffash A, James AT, Corcoran JD, Dicker P, Franklin O, Elsayed YN, et al. A patent ductus arteriosus severity score predicts chronic lung disease or death before discharge. J Pediatr. 2015;167:1354-1361.e2.

6. Canani RB, Terrin G. Recent Progress in congenital diarrheal disorders. Curr Gastroenterol Rep. 2011;13:257-64.

7. Passariello A, Terrin G, et al. Diarrhea in neonatal intensive care unit. World J Gastroenterol. 2010;16:2664.

8. Ferreira CR, van Karnebeek CDM. Inborn errors of metabolism. Handb Clin Neurol. 2019:449-81 Elsevier. Available from: https://linkinghub.elsevier.com/ retrieve/pii/B9780444640291000229. [cited 2020 Jul 29].

9. Nocerino R, Paparo L, Terrin G, Pezzella V, Amoroso A, Cosenza L, et al. Cow's milk and rice fermented with Lactobacillus paracasei CBA L74 prevent infectious diseases in children: a randomized controlled trial. Clin Nutr. 2017; 36:118-25 Available from: https://linkinghub.elsevier.com/retrieve/pii/ S0261561415003416. [cited 2020 Aug 4].

10. Berni Canani R, Di Costanzo M, Pezzella V, Cosenza L, Granata V, Terrin G, et al. The potential therapeutic efficacy of lactobacillus $G G$ in children with food allergies. Pharmaceuticals. 2012;5:655-64 Available from: http://www. mdpi.com/1424-8247/5/6/655. [cited 2020 Aug 4].

11. Salvia G, Cascioli CF, Ciccimarra F, Terrin G, Cucchiara S. A case of proteinlosing enteropathy caused by intestinal lymphangiectasia in a preterm infant. Pediatrics. 2001;107:416-7 Available from: http://pediatrics. aappublications.org/cgi/doi/10.1542/peds.107.2.416. [cited 2020 Aug 4].

12. Kindler A, Seipolt B, Heilmann A, Range U, Rüdiger M, Hofmann SR. Development of a diagnostic clinical score for hemodynamically significant patent ductus arteriosus. Front Pediatr. 2017;5:280.

13. Mellander M, Larsson LE, Ekström-Jodal B, Sabel K-G. Prediction of symptomatic patent ductus arteriosus in preterm infants using doppler and M-mode echocardiography. Acta Paediatr. 1987;76:553-9.

14. Keusters L, Purna J, Deshpande P, Mertens L, Shah P, McNamara PJ, et al. Clinical validity of systemic arterial steal among extremely preterm infants with persistent patent ductus arteriosus. J Perinatol. 2020; Available from: http://www.nature.com/articles/s41372-020-0663-8. [cited 2020 Jul 23].

15. Terrin G, Conte F, Oncel MY, Scipione A, McNamara PJ, Simons S, et al. Paracetamol for the treatment of patent ductus arteriosus in preterm neonates: a systematic review and meta-analysis. Arch Dis Child - Fetal Neonatal Ed. 2016;101:F127-36.

16. Fowlie PW, Davis PG. Prophylactic intravenous indomethacin for preventing mortality and morbidity in preterm infants. In: The Cochrane Collaboration, editor. Cochrane Database Syst Rev. Chichester: Wiley; 2002. p. CD000174. https://doi.org/10.1002/14651858.CD000174. cited 2020 Jul 23.

17. Rolland A, Shankar-Aguilera S, Diomandé D, Zupan-Simunek V, Boileau P. Natural evolution of patent ductus arteriosus in the extremely preterm infant. Arch Dis Child - Fetal Neonatal Ed. 2015;100:F55-8.

18. Terrin G, Coscia A, Boscarino G, Faccioli F, Di Chiara M, Greco C, et al. Longterm effects on growth of an energy-enhanced parenteral nutrition in 
preterm newborn: a quasi-experimental study. Gebremedhin S, editor. Plos One. 2020;15:e235540

19. Terrin G, Boscarino G, Di Chiara M, lacobelli S, Faccioli F, Greco C, et al. Nutritional intake influences zinc levels in preterm newborns: an observational study. Nutrients. 2020;12:529.

20. Terrin G, Berni Canani R, Di Chiara M, Pietravalle A, Aleandri V, Conte F, et al. Zinc in early life: A key element in the fetus and preterm neonate. Nutrients. 2015;7:10427-46.

21. Berni Canani R, Passariello A, Buccigrossi V, Terrin G, Guarino A. The nutritional modulation of the evolving intestine. J Clin Gastroenterol. 2008; 42:S197-200 Available from: http://journals.Iww.com/00004836-20080900200013. [cited 2020 May 6].

22. Terrin G, Passariello A, Canani RB, Manguso F, Paludetto R, Cascioli C Minimal enteral feeding reduces the risk of sepsis in feed-intolerant very low birth weight newborns. Acta Paediatr. 2009;98:31-5. https://doi.org/10 1111/j.1651-2227.2008.00987.x cited 2020 Jan 11.

23. Terrin G, De Nardo MC, Boscarino G, Di Chiara M, Cellitti R, Ciccarelli S, et al. Early protein intake influences neonatal brain measurements in preterms: an observational study. Front Neurol [Internet]. 2020;11:885. Available from: https://www.frontiersin.org/article/10.3389/fneur.2020.00885/full. [cited 2020 Oct 6]

24. Elsayed YN, Fraser D. Patent ductus arteriosus in preterm infants, part 1: understanding the pathophysiologic link between the patent ductus arteriosus and clinical complications. Neonatal Netw. 2017;36: 265-72.

25. Clyman Rl. Patent ductus arteriosus, its treatments, and the risks of pulmonary morbidity. Semin Perinatol. 2018;42:235-42.

26. Brown ER. Increased risk of bronchopulmonary dysplasia in infants with patent ductus arteriosus. J Pediatr. 1979;95:865-6.

27. Dani C, Mosca F, Cresi F, Lago P, Lista G, Laforgia N, et al. Patent ductus arteriosus in preterm infants born at 23-24 weeks' gestation: should we pay more attention? Early Hum Dev. 2019;135:16-22.

28. Schena F, Francescato G, Cappelleri A, Picciolli I, Mayer A, Mosca F, et al. Association between hemodynamically significant patent ductus arteriosus and bronchopulmonary dysplasia. J Pediatr. 2015;166:1488-92.

29. Clyman RI. The role of patent ductus arteriosus and its treatments in the development of bronchopulmonary dysplasia. Semin Perinatol. 2013;37:1027.

30. Willis KA, Weems MF. Hemodynamically significant patent ductus arteriosus and the development of bronchopulmonary dysplasia: Willis and Weems. Congenit Heart Dis. 2019;14:27-32. https://doi.org/10.1111/chd.12691 cited 2020 Nov 2.

31. Marshall DD, Kotelchuck M, Young TE, Bose CL, Kruyer L, O'Shea TM, et al. Risk factors for chronic lung disease in the surfactant era: a North Carolina population-based study of very low birth weight infants. Pediatrics. 1999; 104:1345-50.

32. Sung Sl, Chang YS, Chun JY, Yoon SA, Yoo HS, Ahn SY, et al. Mandatory Closure versus nonintervention for patent ductus arteriosus in very preterm infants. J Pediatr. 2016;177:66-71 e1.

33. Semberova J, Sirc J, Miletin J, Kucera J, Berka I, Sebkova S, et al. Spontaneous closure of patent ductus arteriosus in infants $\leq 1500 \mathrm{~g}$. Pediatrics. 2017;140:e20164258.

34. Hwang JS, Rehan VK. Recent advances in bronchopulmonary dysplasia: pathophysiology, prevention, and treatment. Lung. 2018;196: 129-38.

35. Cavallaro G, Filippi L, Bagnoli P, La Marca G, Cristofori G, Raffaeli G, et al. The pathophysiology of retinopathy of prematurity: an update of previous and recent knowledge. Acta Ophthalmol (Copenh). 2014;92:2-20. https://doi.org/ 10.1111/aos. 12049 cited 2020 Nov 2.

36. Abu-Shaweesh JM, Almidani E. PDA: does it matter? Int J Pediatr Adolesc Med. 2020;7:11-4.

37. Noori S, McCoy M, Friedlich P, Bright B, Gottipati V, Seri I, et al. Failure of ductus arteriosus closure is associated with increased mortality in preterm infants. Pediatrics. 2009;123:e138-44.

38. Verma RP, Dasnadi S, Zhao Y, Chen HH. Complications associated with the current sequential pharmacological management of early postnatal hypotension in extremely premature infants. Bayl Univ Med Cent Proc. 2019; 32:355-60.

39. Ruoss JL, Bazacliu C, Giesinger RE, McNamara PJ. Patent ductus arteriosus and cerebral, cardiac, and gut hemodynamics in premature neonates. Semin Fetal Neonatal Med. 2020;25(5):101120.
40. Auger N, Fraser WD, Healy-Profitós J, Arbour L. Association between preeclampsia and congenital heart defects. JAMA. 2015;314:1588.

41. Yilgwan CS, Pam VC, Ige OO, Golit WN, Anzaku S, Imade GE, et al. Profile of congenital heart disease in infants born following exposure to preeclampsia. Xie L, editor. Plos One. 2020;15:e0229987.

42. Boyd HA, Basit S, Behrens I, Leirgul E, Bundgaard H, Wohlfahrt J, et al. Association between fetal congenital heart defects and maternal risk of hypertensive disorders of pregnancy in the same pregnancy and across pregnancies. Circulation. 2017;136:39-48.

43. Sosenko IRS, Fajardo MF, Claure N, Bancalari E. Timing of patent ductus arteriosus treatment and respiratory outcome in premature infants: a double-blind randomized controlled trial. J Pediatr. 2012;160:929-935.e1.

44. Mahony L, Carnero V, Brett C, Heymann MA, Clyman Rl. Prophylactic indomethacin therapy for patent ductus arteriosus in very-low-birth-weight infants. N Engl J Med. 1982;306:506-10.

45. Van Overmeire B, Van de Broek H, Van Laer P, Weyler J, Vanhaesebrouck P. Early versus late indomethacin treatment for patent ductus arteriosus in premature infants with respiratory distress syndrome. J Pediatr. 2001;138: 205-.

\section{Publisher's Note}

Springer Nature remains neutral with regard to jurisdictional claims in published maps and institutional affiliations.
Ready to submit your research? Choose BMC and benefit from:

- fast, convenient online submission

- thorough peer review by experienced researchers in your field

- rapid publication on acceptance

- support for research data, including large and complex data types

- gold Open Access which fosters wider collaboration and increased citations

- maximum visibility for your research: over $100 \mathrm{M}$ website views per year

At BMC, research is always in progress.

Learn more biomedcentral.com/submissions 